\title{
Decomplexifying Serum and Cerebrospinal Fluid (CSF) Serologic Testing of Neurosyphilis: A Case Report of Ocular Syphilis and Highlights of the Principles of Serologic Testing
}

\author{
Hassan Kesserwani ${ }^{1}$ \\ 1. Neurology, Flowers Medical Group, Dothan, USA
}

Corresponding author: Hassan Kesserwani, neuro1815@yahoo.com

\begin{abstract}
Serologic tests for syphilis can be quite complex. The screening and confirmatory tests, which number at least eight, are mathematically interpreted as a total of 16 possible combinations, if we choose one test from each of two sets of four. However, this bewildering complexity is simplified if we apply certain principles. We reiterate and propose four axioms. First, we distinguish between treponemal versus non-treponemal tests. The former, the treponemal test, is specific for the spirochete, treponema pallidum, and is used as a confirmatory test. It rarely declines over time. The latter, the non-treponemal test, is a screening test and reflects treponemal or tissue damage, is reported as a titer, and is used to monitor disease activity. We usually need both for screening and confirmatory diagnostic testing. Secondly, for rapid plasma reagin (RPR) tests, a non-treponemal serology test titer of at least 1:8 is suggestive of syphilis, but not necessarily neurosyphilis. A false-negative test usually registers below this dilution level and may be due to the "prozone phenomenon". Serum RPR titers are usually greater than $1: 32$. Thirdly, a negative treponemal test in the cerebrospinal fluid excludes neurosyphilis and a positive test is highly sensitive but lacks specificity, usually due to blood contamination. Most patients with neurosyphilis will have a positive non-treponemal test in the cerebrospinal fluid (CSF) with elevated protein and pleocytosis. Fourthly, a serological cure is defined as at least a four-fold decline in a non-treponemal test titer at three and six months, or a persistently low titer after treatment. Patients who do not fulfill these criteria are known as "serofast". We describe the case of a 38-year-old man with human immunodeficiency virus-type 1 who developed bilateral optic disc edema with photopsias and transient visual obscurations.
\end{abstract}

Review began 10/18/2020 Review ended 11/01/2020 Published 11/17/2020

() Copyright 2020

Kesserwani. This is an open access article distributed under the terms of the Creative Commons Attribution License CC-BY 4.0., which permits unrestricted use, distribution, and reproduction in any medium, provided the original author and source are credited.

Categories: Neurology, HIV/AIDS, Infectious Disease

Keywords: invasive bacterial infections, hiv diseases, serology testing, treponema pallidum

\section{Introduction}

Syphilis is caused by the spirochete, Treponema pallidum (Tp), a spiral shaped bacterium, with a unique morphology and elusive character that has challenged mankind for centuries. The spirochete is surrounded by a cytoplasmic membrane, periplasmic space and a loose outer membrane devoid of antigens. This structural trifecta explains a lot of the mystery and halo surrounding $\mathrm{Tp}[1]$.

Remarkably, Tp cannot be cultured in vitro, making it a tough organism to diagnose and study [2]. Another remarkable feature is Tp's heat sensitivity. The Nobel prize in medicine and physiology in 1927 was awarded to Julius Wagner-Jauregg for pyrotherapy with the malaria parasite and the treatment of neurosyphilis. Patients with advanced neurosyphilis, general paralysis of the insane, were inoculated with Plasmodium falciparum parasites, and high fevers led to remission both clinically and by cerebrospinal fluid examination [3]. This heat fragility of Tp is thought to be due to the heat-labile enzyme, 3-phosphoglycerate mutase, a key enzyme of the Embden-Meyerhof pathway for generating adenosine triphosphate (ATP) [4]. The denuded outer membrane of $\mathrm{Tp}$, meaning its paucity of integral membrane proteins, exposes transmembrane proteins that are not immunogenic, rendering the Tp spirochete a "stealth bullet" that can multiply freely in the skin before the phagocytic action of Langerhans cells and macrophages are activated, partly explaining the pernicious nature of the bacterium and its elusive persistence in the human body [5].

The natural history of syphilis is complex with multiple stages - primary syphilis with a chancre at site of infection and regional adenopathy, secondary syphilis with a disseminated rash and generalized adenopathy, latent syphilis with recurrence of secondary syphilis in up to $25 \%$ of individuals and tertiary syphilis with gumma, syphilitic aortitis, tabes dorsalis, general paresis of the insane and ocular syphilis [6].

Each stage has its own complement of tests with latency and duration, some of which overlap. The tests come in two categories: treponemal tests (T-tests) and non-treponemal tests (NT-tests). A detailed account will follow in the Discussion section. However, at the outset we will note a striking finding with a T-test, the rapid plasma reagin (RPR) test; a serum RPR greater than or equal to a dilution factor of 1:32 is significantly associated with neurosyphilis in the setting of ocular or neurologic symptoms [7]. In the Discussion section, 


\section{Cureus}

we will outline the four basic principles that will help us navigate the multitude of T- and NT-tests.

We present the case of a 38-year-old man, with human immunodeficiency virus-type 1 (HIV-1), who developed bilateral optic disc edema associated with photopsias and transient visual obscurations, with serology and cerebrospinal findings diagnostic of neurosyphilis. These constellations of findings suggested a presumptive diagnosis of ocular syphilis. Whereas there have been several excellent reports of ocular syphilis reported in the Cureus Medical Journal over the last several years, we seize upon this opportunity to use this case report to navigate the complex waters of the serological testing of neurosyphilis. We will address many of the nuances of these tests and propose four axioms that will help decomplexify serological and cerebrospinal fluid testing.

\section{Case Presentation}

We describe the case of a 38-year-old man with HIV who has had a one-year history of blurring of vision, intermittent flashing lights and occasional transient visual obscurations with position change. He denied any headaches or tinnitus. A visit to the ophthalmologist led to a diagnosis of bilateral papilledema.

His past medical history was significant for hypertension, diabetes, hyperlipidemia and bipolar disease. His medications included emtricitabine-tenofovir 200/300 milligrams (mg) once daily, bupropion $150 \mathrm{mg}$ daily, cimetidine $200 \mathrm{mg}$ twice daily, hydrochlorothiazide $25 \mathrm{mg}$ daily, losartan $100 \mathrm{mg}$ daily, metformin $500 \mathrm{mg}$ daily, atorvastatin $40 \mathrm{mg}$ daily and quetiapine $200 \mathrm{mg}$ daily.

On examination, his blood pressure (BP) was 122/77 mmg, pulse of 85 beats per minute, weight of 231 pounds, with height of 71 inches and body mass index (BMI) of 31.1. Precordial chest examination did not reveal a cardiac murmur. His neurological examination was entirely normal. Funduscopic eye examination revealed bilateral optic disc edema with peri-papillary flame hemorrhages and cotton-wool spots (Figure 1).

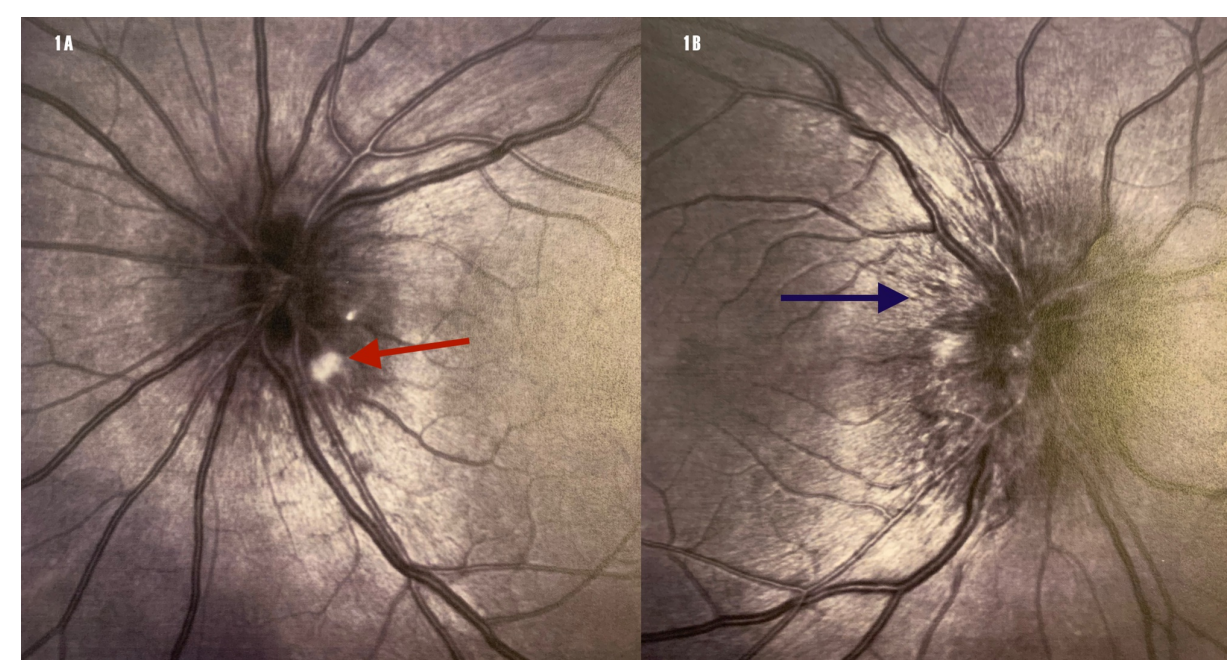

FIGURE 1: Funduscopic eye exam. Bilateral optic disc edema.

1A - right eye, cotton-wool spot (red arrow). 1B - left eye, severe optic disc edema (blue arrow).

A magnetic resonance imaging (MRI) of the brain with and without gadolinium contrast, magnetic resonance venogram of the brain and MRI of the orbits with and without contrast gadolinium were all normal.

The cluster of differentiation (CD-4) white cell count was 1392 (>500 cells/cubic millimeter). Serum RPR titer was very high at $1: 128(<1: 8)$. A lumbar puncture revealed an opening pressure of $20 \mathrm{~cm}$ of water $(<25)$ in the lateral decubitus position. Cerebrospinal fluid (CSF) results are listed below (Table 1). 


\section{Cureus}

\begin{tabular}{|c|c|c|c|c|c|c|}
\hline RPR & FTA-ABS & VDRL & PROTEIN & WBC COUNT & OCB & $\begin{array}{l}\text { IgG } \\
\text { INDEX }\end{array}$ \\
\hline $\begin{array}{l}1: 64 \\
(1: 8)\end{array}$ & $\begin{array}{l}\text { Reactive (titer not } \\
\text { reported) }\end{array}$ & $\begin{array}{l}\text { Reactive (titer not } \\
\text { reported) }\end{array}$ & $\begin{array}{l}50.2(>44 \\
\mathrm{mg} / \mathrm{ml})\end{array}$ & $\begin{array}{l}5 \text { ( }<5 \text { cells per } \\
\text { microliter) }\end{array}$ & $\begin{array}{l}1 \text { band } \\
(<4)\end{array}$ & $0.6(<0.7)$ \\
\hline
\end{tabular}

\section{TABLE 1: Cerebrospinal fluid (CSF) results displaying typical profile of neurosyphilis.}

RPR: Reactive plasma reagin, VDRL: Venereal disease research laboratory, FTA-ABS: Fluorescent treponemal antibody absorption test, WBC: White blood cell count, OCB: Oligoclonal bands, IgG: Immunoglobulin G, mg/ml: milligram per millilter.

The serum and CSF serology displays the typical signature of neurosyphilis. We have a high titer serum NTtest, RPR, and a positive CSF T-test, fluorescent treponemal antibody absorption test (FTA-ABS), and in this case two positive CSF NT-tests, RPR and venereal disease research laboratory (VDRL). CSF RPR is usually of low sensitivity. We believe our patient did not display a significant pleocytosis because he had received two empirical doses of intramuscular procaine penicillin from the HIV clinic two weeks prior to the lumbar puncture. Following the lumbar puncture, our patient received the standard therapeutic protocol for ocular syphilis; 1.2 million units of intramuscular procaine penicillin daily for 14 days plus probenecid $500 \mathrm{mg}$ four times daily for 14 days. A repeat lumbar puncture is planned in three months in order to demonstrate a fourfold drop in serum NT-test titers, in this case the RPR. A lumbar puncture will also be performed four weeks after the last dose of procaine penicillin to assess CSF VDRL status.

\section{Discussion}

We will classify our four principles as axioms. Our first axiom addresses the cardinal difference between Ttests and NT-tests. The T-tests are confirmatory tests that are specific to the spirochete, Tp. They usually do not decline over time. Meanwhile, the NT-tests are used as a screening test, detect Tp damage and/or tissue injury secondary to Tp. NT-tests are reported as dilution titers and are excellent markers of disease activity. The differences between T-tests and NT-tests are listed below (Table 2) [8].

\section{TREPONEMAL TESTS (T-test)}

Tp or its components as antigen

Do not correlate with disease activity or therapy can stay positive for many years

For confirmation of non-treponemal tests

Do not differentiate between different species of spirochetes

Non-reactive test means no current or past infection

FTA-ABS, TP-PA, EIA, Western Blot,

Cumbersome

\section{NON-TREPONEMAL TESTS (NT-test)}

IgG or IgM against lipoidal molecules from Tp or host cell

For monitoring disease activity

For screening

Lower sensitivity in primary syphilis and late latent syphilis, also false-positive due to cross-reactivity and false-negative rates

VDRL, RPR, USR, TRUST

Rapid and simple

\section{TABLE 2: Key features distinguishing treponemal from non-treponemal tests.}

Tp: Treponema pallidum, IgM: Immunoglobulin M, IgG: Immunoglobulin G, FTA-ABS: Fluorescent treponemal antibody absorption, TP-PA: Treponema pallidum particle agglutination, EIA: Enzyme immuno-assay, VDRL: Venereal disease research laboratory, RPR: Rapid plasma reagin, USR: Unheated serum reagin, TRUST: Toluidine red unheated serum test.

A brief but comprehensive overview of the main screening, NT-tests, and confirmatory tests, T-tests, is outlined below (Table 3) [8]. 


\section{Cureus}

\begin{tabular}{|c|c|c|c|c|c|c|c|}
\hline FTA-ABS & TP-PA & EIA & WB & VDRL & RPR & USR & TRUST \\
\hline $\begin{array}{l}\text { Indirect } \\
\text { fluorescent } \\
\text { antibody - } \\
\text { absorbent }\end{array}$ & $\begin{array}{l}\text { Ip antigen + gelatin } \\
\text { particles - } \\
\text { microagglutination } \\
\text { with Tp antibody }\end{array}$ & Detects $\lg G$ & $\begin{array}{l}\text { Detected } \\
\text { IgM and } \\
\text { IgG } \\
\text { banding }\end{array}$ & $\begin{array}{l}\text { Micro- } \\
\text { flocculation, } \\
\text { quantitative, } \\
\text { phospholipid- } \\
\text { based }\end{array}$ & $\begin{array}{l}\text { Macro-flocculation, } \\
\text { quantitative, phospholipid- } \\
\text { based }\end{array}$ & $\begin{array}{l}\text { Micro- } \\
\text { flocculation, } \\
\text { quantitative, } \\
\text { phospholipid- } \\
\text { based }\end{array}$ & $\begin{array}{l}\text { Macro- } \\
\text { flocculation } \\
\text { quantitative, } \\
\text { phospholipid- } \\
\text { based }\end{array}$ \\
\hline $\begin{array}{l}\text { Laboratory } \\
\text { dependent }\end{array}$ & Can use naked eyes & $\begin{array}{l}\text { For screening and } \\
\text { detection - but } \\
\text { reaction can be } \\
\text { life-long }\end{array}$ & & $\begin{array}{l}\text { Antigen } \\
\text { suspension has } \\
\text { to be prepared } \\
\text { daily }\end{array}$ & $\begin{array}{l}\text { Simpler version of VDRL } \\
\text { test -uses charcoal } \\
\text { particles }\end{array}$ & & $\begin{array}{l}\text { Toluidine red } \\
\text { particles }\end{array}$ \\
\hline $\begin{array}{l}\text { High } \\
\text { sensitivity } \\
\text { and } \\
\text { specificity }\end{array}$ & $\begin{array}{l}\text { High sensitivity and } \\
\text { specificity }\end{array}$ & $\begin{array}{l}\text { Highest sensitivity } \\
\text { of all treponemal } \\
\text { tests }\end{array}$ & $\begin{array}{l}\text { very high } \\
\text { specificity }\end{array}$ & $\begin{array}{l}\text { Only non- } \\
\text { treponemal test } \\
\text { used for CSF }\end{array}$ & $\begin{array}{l}\text { False-positive usually has a } \\
\text { titer of less than } 1: 8 \text {. In } \\
\text { neurosyphilis, titers at least } \\
1: 32\end{array}$ & & \\
\hline
\end{tabular}

TABLE 3: Comparing the different treponemal and non-treponemal tests.

Tp: Treponema pallidum, IgM: Immunoglobulin M, IgG: Immunoglobulin G, FTA-ABS: Fluorescent treponemal antibody absorption, TP-PA: Treponema pallidum particle agglutination, EIA: Enzyme immuno-assay, VDRL: Venereal disease research laboratory, RPR: Rapid plasma reagin, USR: Unheated serum reagin, TRUST: Toluidine red unheated serum test, WB: Western blot, CSF: Cerebrospinal fluid.

The key take home points from Table 3 are that the only consistent NT-test for CSF is the VDRL test and that a serum RPR titer less than 1:8 is usually false positive, and may be due to other auto-immune diseases [9]. Our second axiom states that in neurosyphilis, serum RPR titers are usually at least 1:32 [7,10].

Next, we will explore the phenomenon of the "prozone" effect, which can lead to false-negative testing. Antigen-antibody interactions lead to complexes, which can be visible with a microscope, microflocculation, or the naked eye, macro-flocculation. There are optimal antigen and antibody levels that optimize the interaction, the "zone of equivalence". Outside this zone, too much antibody interferes with immune complex deposition and flocculation, the "prozone" effect. Too much antigen interferes with immune complex formation leading to the "postzone" effect. Geometrically stated, too many antibody molecules prevent them from cross-linking and precipitating, as lattice formation requires symmetry and equivalent numbers of antigen and antibody molecules (Figure 2) [11].

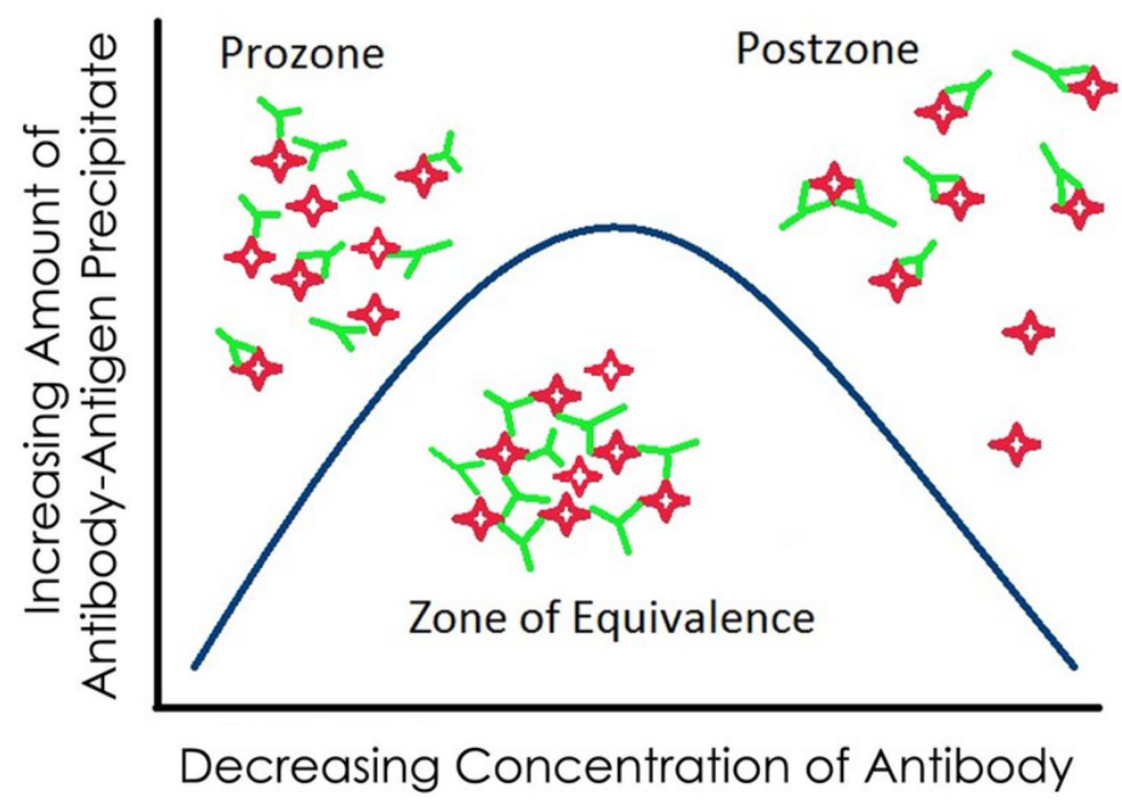

T Antibody

Antigen 


\section{Cureus}

FIGURE 2: Precipitation curve explaining the "prozone" phenomenon.

The diagnosis of neurosyphilis requires the triad of CSF inflammation, pleocytosis and elevated protein, and a positive CSF T-test and NT-test, the latter reflecting ongoing tissue damage of Tp parasite or the host cell or both (Table 4) [12].

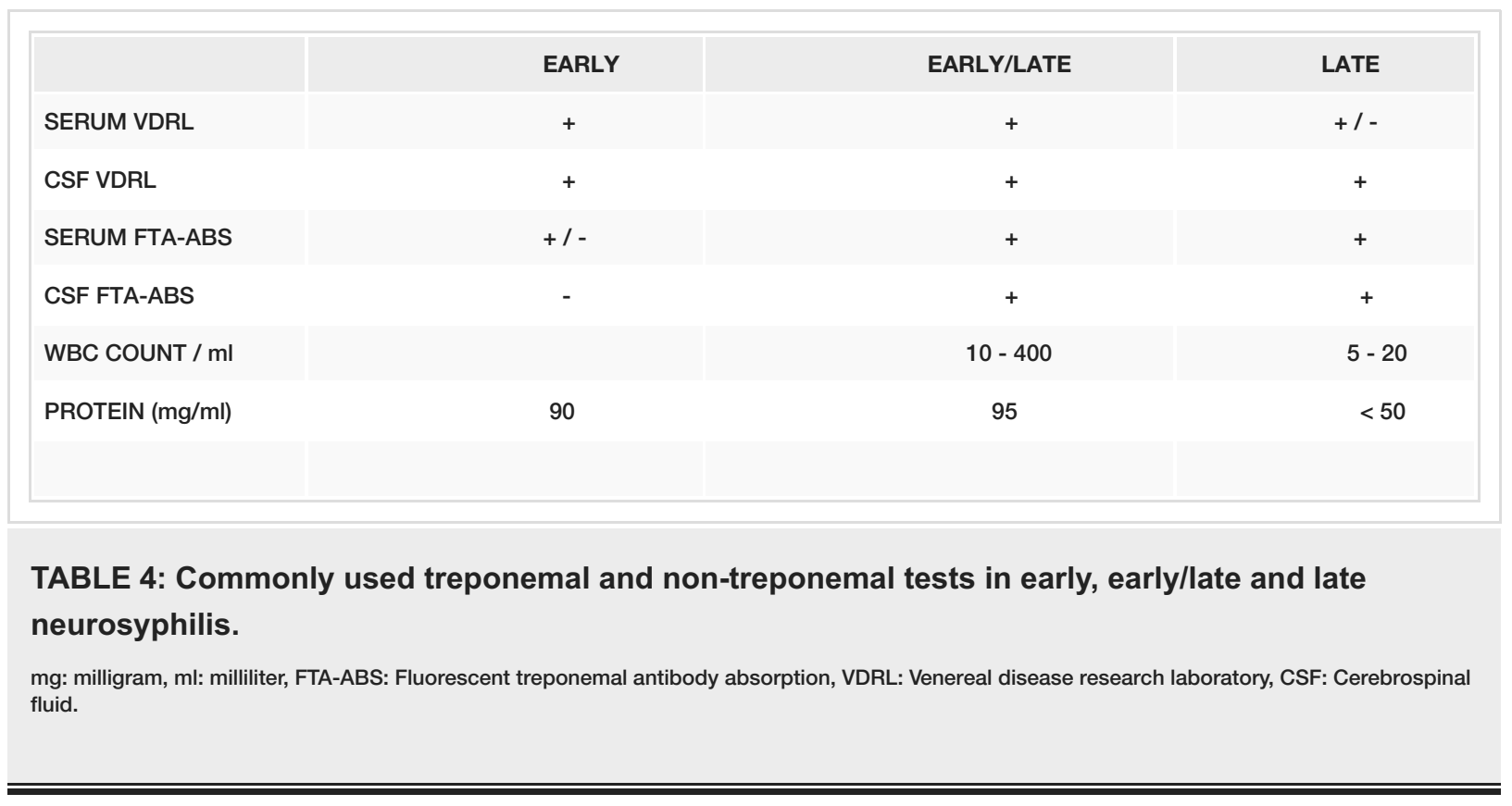

It is generally recommended that one perform CSF analysis in HIV-patients with neurologic or ophthalmologic signs and findings, when RPR titers are greater than 1:32 or a cluster of differentiation (CD4) count of less than 350 cells per microliter. Even though CSF VDRL, an NT-test, is highly specific for neurosyphilis, its sensitivity is low, usually below 70\%. A CSF pleocytosis greater than 20 leukocytes per microliter is helpful but not conclusive. A T-test, such as FTA-ABS, has a high negative predictive value, that is, if negative, then the patient does not have neurosyphilis, our third axiom [13,14].

A recurring theme is the observation that T-tests, specific tests against the Tp spirochete, persist in the serum and CSF in patients with syphilis, while NT-tests, which reflect Tp and host tissue damage decline with treatment. The trajectory of the most commonly used serological markers, VDRL, an NT-test, and FTAABS, a T-test, in the various stages of syphilis are displayed below for serum and CSF and as expected the Ttest remains stable and the NT-tests decline over time (Figure 3) [15]. 


\section{Cureus}

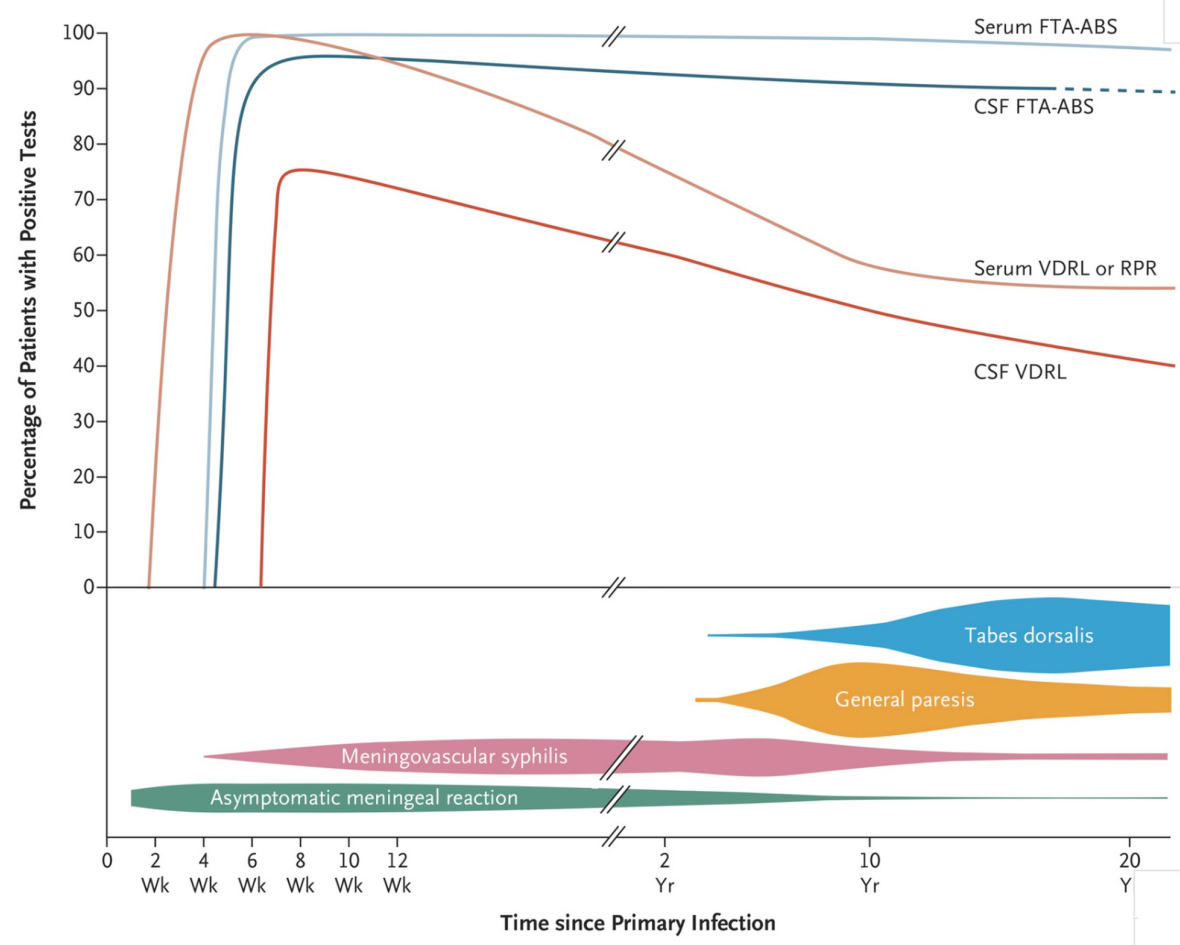

FIGURE 3: Sensitivity of most commonly used treponemal and nontreponemal tests in the natural history neurosyphilis.

CSF: Cerebrospinal fluid, FTA-ABS: Fluorescent treponemal absorption test, VDRL: Venereal disease research laboratory, RPR: Rapid plasma reagin, Wk: Week, Yr: Year.

With standard therapy of syphilis, an NT-test such as an RPR, should demonstrate at least a four-fold decline in titers by three months or an eight-fold decline by six months. This is our fourth and last axiom. One should note that $15 \%$ of patients fail to meet these criteria especially with HIV co-infection. The decline in titers can be a slow process and these patients are known as "serofast" [16,17]. It is well established that HIV co-infection increases the rate of neurologic and ophthalmologic complications and increases the frequency of false-negative serology $[18,19]$.

Finally, polymerase chain reaction (PCR) has a limited role in syphilitic testing. In early and primary syphilis, serum and CSF sensitivity of PCR testing is close to $90 \%$ and specificity close to $100 \%$. The sensitivity drops dramatically to $50 \%$ in secondary syphilis [20].

\section{Conclusions}

The panorama of serological testing for syphilis and neurosyphilis is intimidating. In order to weave through this complex web of testing, we streamlined the data into four principles or axioms. This set of four principles is not all-inclusive, but does provide a comprehensive framework for patient management. In summary, our first axiom states that T-tests are confirmatory tests, treponema-specific and good for confirmation, whereas NT-tests are screening tests that monitor disease activity. We usually need both for confirming a diagnosis and monitoring disease. Our second axiom states that a serum RPR titer less than 1:8 is likely false positive, and neurosyphilis is usually associated with an RPR titer greater than 1:32. Falsenegativity may be due to the prozone effect. Our third axiom states that it is highly unlikely to suffer from neurosyphilis if a T-test such as FTA-ABS is negative in the CSF. Our fourth axiom states that treatment responsiveness translates to at least a four-fold drop of serum titers at three months, or an eight-fold drop in serum titers at six months of an NT-test. A lack of a response is usually known as serofast. We believe that stratifying these tests helps in streamlining the diagnostic process. Meanwhile, these criteria will continue to be updated with the advent of new technology and new clinical studies.

\section{Additional Information}

\section{Disclosures}

Human subjects: Consent was obtained by all participants in this study. Conflicts of interest: In compliance with the ICMJE uniform disclosure form, all authors declare the following: Payment/services info: All authors have declared that no financial support was received from any organization for the 
submitted work. Financial relationships: All authors have declared that they have no financial relationships at present or within the previous three years with any organizations that might have an interest in the submitted work. Other relationships: All authors have declared that there are no other relationships or activities that could appear to have influenced the submitted work.

\section{References}

1. Jepsen OB, Hougen KH, Birch-Andersen A: Electron microscopy of Treponema pallidum Nichols . Acta Pathol Microbiol Scand. 1968, 74:241-258. 10.1111/j.1699-0463.1968.tb03477.x

2. Norris SJ, Edmondson DG: Factors affecting the multiplication and subculture of Treponema pallidum subsp. pallidum in a tissue culture system. Infect Immun. 1986, 53:534-539.

3. von Jauregg WJ: Uber die Einwirkung der Malaria auf die progressive Paralyse . Psychiatr Neurol Wochenschr. 1918, 20:132.

4. Benoit S, Posey JE, Chenoweth MR, Gherardini FC: Treponema pallidum 3-phosphoglycerate mutase is a heat-labile enzyme that may limit the maximum growth temperature for the spirochete. J Bacteriol. 2001, 83:4702-4708. 10.1128/JB.183.16.4702-4708.2001

5. Radolf JD, Kumar S: The Treponema pallidum outer membrane. In: Spirochete Biology: The Post Genomic Era. Current Topics in Microbiology and Immunology. Adler B (ed): Springer, Cham; 2017. 415:10.1007/82_2017_44

6. Gjestland T: The Oslo study of untreated syphilis; an epidemiologic investigation of the natural course of the syphilitic infection based upon a re-study of the Boeck-Bruusgaard material. Acta Derm Venereol Suppl (Stockh). 1955, 35:3-368.

7. Marra CM, Maxwell CL, Smith SL, et al.: Cerebrospinal fluid abnormalities in patients with syphilis: association with clinical and laboratory features. J Infect Dis. 2004, 189:369-376. 10.1086/381227

8. Larsen SA, Steiner BM, Rudolph AH: Laboratory diagnosis and interpretation of tests for syphilis . Clin Microbiol Rev. 1955, 8:1-21. 10.1128/CMR.8.1.1

9. Peter CR, Thompson MA, Wilson DL: False-positive reactions in the rapid plasma reagin-card, fluorescent treponemal antibody-absorbed, and hemagglutination treponemal syphilis serology tests. J Clin Microbiol. 1979, 9:369-372.

10. Marra CM, Maxwell CL, Tantalo LC, Sahi SK, Lukehart SA: Normalization of serum rapid plasma reagin titer predicts normalization of cerebrospinal fluid and clinical abnormalities after treatment of neurosyphilis. Clin Infect Dis. 2008, 47:893-899. 10.1086/591534

11. Jurado RL, Campbell J, Martin PD: Prozone phenomenon in secondary syphilis. Has its time arrived? . Arch Intern Med. 1993, 153:2496-2498. 10.1001/archinte.1993.00410210124014

12. Dumaresq J, Langevin S, Gagnon S, et al.: Clinical prediction and diagnosis of neurosyphilis in HIV-infected patients with early syphilis. J Clin Microbiol. 2013, 51:4060-4066. 10.1128/JCM.01989-13

13. French P, Gomberg M, Janier M, Schmidt B, van Voorst Vader P, Young H: IUSTI: 2008 European guidelines on the management of syphilis. Int J STD AIDS. 2009, 20:300-309. 10.1258/ijsa.2008.008510

14. Hart G: Syphilis tests in diagnostic and therapeutic decision making. Ann Intern Med. 1986, 104:368-376. 10.7326/0003-4819-104-3-368

15. Roper AH: Neurosyphilis. N Engl J Med. 2019, 381:1358-1363. 10.1056/NEJMra1906228

16. Brown ST, Zaidi A, Larsen SA, Reynolds GH: Serological response to syphilis treatment. A new analysis of old data. JAMA. 1985, 253:1296-1299.

17. Ratnam S: The laboratory diagnosis of syphilis . Can J Infect Dis Med Microbiol. 2005, 16:7. 10.1155/2005/597580

18. Lynn WA, Lightman S: Syphilis and HIV: a dangerous combination . Lancet Infect Dis. 2004, 4:456-466 10.1016/S1473-3099(04)01061-8

19. Chan DJ: Syphilis and HIV co-infection: when is lumbar puncture indicated? . Curr HIV Res. 2005, 3:95-98. 10.2174/1570162052773031

20. Zhou C, Zhang X, Zhang W, Duan J, Zhao F: PCR detection for syphilis diagnosis: status and prospects . J Clin Lab Analysis. 2019, 33:e22890. 10.1002/jcla.22890 